\title{
Unilateral negative pres- sure pulmonary edema during anesthesia with a laryngeal mask airway
}

Purpose: To present a case of unilateral pulmonary edema after upper airway obstruction.

Clinical Features: In a 21 -yr-old man, anesthesia was induced with propofol and maintained with $\mathrm{N}_{2} \mathrm{O} / \mathrm{O}_{2} /$ isoflurane via an LMA. After being placed in the lateral position, he had an episode of upper airway obstruction while breathing spontaneously. Hypoxemia $\left(\mathrm{SpO}_{2} 80-83 \%\right)$ refractory to the administration of oxygen $\left(\mathrm{F}_{1} \mathrm{O}_{2} \mid .0\right)$ ensued following relief of the obstruction. Chest $\mathrm{X}$-ray showed edema of the dependent lung. Treatment consisted of placing the patient in the sitting position and supplemental oxygen. The situation resolved over a few hours.

Conclusion: If airway obstruction occurs in the lateral position, development of negative pressure pulmonary edema (NPPE) in the dependent lung is favoured by hydrostatic forces and possibly the elevated resting position of the dependent hemidiaphragm.

Objectif : Présenter un cas d'œdème pulmonaire unilatéral suivant une obstruction des voies aériennes.

Éléments cliniques : L'anesthésie a été induite et maintenue avec $\mathrm{N}_{2} \mathrm{O} / \mathrm{O}_{2}$ et de l'isoflurane au moyen d'un $\mathrm{ML}$ chez un homme de 21 ans. Une fois en positions latérale, il a connu un épisode d'obstruction des voies aériennes supérieures pendant la respiration spontanée. L'hypoxémie $\left(\mathrm{SpO}_{2} 80-83 \%\right)$ résistante à l'administration d'oxygène $\left(\mathrm{F}_{1} \mathrm{O}_{2} \mathrm{I}, 0\right)$ a suivi le traitement de l'obstruction. Les radiographies du thorax ont montré un œdème du poumon déclive. On a fait asseoir le patient pour l'oxygénothérapie. Le patient s'est rétabli après quelques heures.

Conclusion : Si une obstruction des voies aériennes survient en position latérale, l'apparition d'un cedème pulmonaire de pression négative (OPPN) est provoqué par les forces hydrostatiques et probablement par la position surélevée et au repos de l'hémidiaphragme déclive.

From the Department of Anaesthesia and Intensive Care, Cairns Base Hospital, Cairns, Queensland, Australia. Address correspondence to: Dr. Michael Sullivan, Department of Anesthesia, York County Hospital, 596 Davis Drive, Newmarket, Ontario L3Y 2P9 Canada. E-mail: kellmatt@interlog.com Accepted for publication July $31,1999$. 
$\mathrm{N}$

EGATIVE pressure pulmonary edema (NPPE) is an uncommon but well recognized clinical entity, which occurs after the relief of upper airway obstruction in a spontaneously breathing patient. The majority of reported cases are associated with anesthesia related airway obstruction in the perioperative period. In a thorough review of the subject, Lang et al. ${ }^{1}$ suggest that the pathogenesis is multifactorial. The inciting pathophysiological event is the development of supranormal negative intrathoracic pressure. This leads directly to derangements of the cardiovascular system and alters the Starling forces, both of which favour the development of pulmonary edema. Failure to ventilate (hypoxia, hypercarbia) has both direct and indirect actions on the cardiopulmonary system, and will promote a hyperadrenergic state which also favours the formation of pulmonary edema.

Recently, two reports of unilateral NPPE have appeared. Betts and Eggan ${ }^{2}$ reported a case of unilateral NPPE following laryngeal spasm on emergence from general anesthesia in the presence of an interscalene block. Bourke ${ }^{3}$ reported a case of unilateral NPPE, which occurred post extubation, following laryngospasm in the lateral position. This clinical report describes another case of unilateral pulmonary edema, which occurred after an episode of airway obstruction in the lateral position, during anesthesia with a Laryngeal Mask Airway(LMA).

\section{Case Report}

The patient was a 21 -yr-old man, previous multiple trauma victim, who presented for elective removal of a right intramedullary femoral nail. He had a medical history of mild asthma, which required occasional use of a salbutamol inhaler, and a five pack year history of cigarette smoking. The rest of the history was unremarkable. The patient took no other medications and there was no history of esophageal reflux symptoms. Previous general anesthesia for orthopedic procedures had been without anesthesia related problems. Physical examination revealed a fit young man, 175 $\mathrm{cm}, 68 \mathrm{~kg}$, and BP 124/80 mm Hg, HR $72 \mathrm{Bpm}$ and regular. The airway appeared to be easily accessible to orotracheal intubation. Cardiovascular examination was unremarkable. Chest auscultation revealed a few coarse inspiratory sounds bilaterally, which cleared with coughing, and no expiratory wheeze.

No premedication was given. Routine monitors were applied before anesthesia which was induced with $0.2 \mathrm{mg}$ fentanyl and $200 \mathrm{mg}$ propofol $i v$ while the patient was breathing $\mathrm{O}_{2} 100 \%$. A \#4 LMA was placed and the cuff inflated to a $15 \mathrm{~cm} \mathrm{H}_{2} \mathrm{O}$ seal; no bite block was used. Manual ventilation was established with $\mathrm{O}_{2} 100 \%$. Thereafter, the lungs were manually ventilated with $\mathrm{N}_{2} \mathrm{O} 70 \%$ and oxygen ( $6 \mathrm{~L} \cdot \mathrm{min}^{-1} \mathrm{FGF}$ ), with the isoflurane vaporiser set at $2 \%$. The procedure required the patient to be moved into the left lateral position. During positioning, the patient began to cough and clench his teeth upon the LMA. A series of obstructed respiratory efforts followed and manual ventilation was not possible. It was not clear whether the level of obstruction was at the level of the teeth or the larynx. No attempt was made to deflate the LMA. Propofol, $100 \mathrm{mg} i v$, was given followed by $60 \mathrm{mg}$ succinylcholine. Ventilation was re-established. During the course of events the $\mathrm{O}_{2}$ saturation decreased to the low 80 s. Oxygen, $100 \%$, was delivered. Spontaneous ventilation resumed and was assisted, and an attempt was made to deliver PEEP. Despite these measures, the $\mathrm{SpO}_{2}$ remained at $84-86 \%$. Chest auscultation revealed coarse breath sounds, $\mathrm{L}>\mathrm{R}$, no wheeze, and no notable prolongation of the expiratory phase. No material was found on suctioning the LMA.

The procedure was abandoned and the patient returned to the supine position with an improvement in the $\mathrm{SpPO}_{2}$ to $92-93 \%$ breathing $\mathrm{O}_{2} \quad 100 \%$. Isoflurane was discontinued and the patient was allowed to regain consciousness. The LMA was removed and the $\mathrm{SpO}_{2}$ while breathing $\mathrm{O}_{2} 100 \%$ via the anesthetic circuit was $91 \%$. The patient was moved to Recovery Room coughing incessantly. High flow $\mathrm{O}_{2}$ was administered via facemask. Nebulized salbutamol was given because of a concern regarding reactive airways disease. Chest $\mathrm{X}$-ray (Figure) demonstrated marked increase in left sided extravascular lung water and a normal $\mathrm{R}$ side. Clinically, the patient improved rapidly with no further intervention. After two hours he had a $\mathrm{SpO}_{2}$ of $90 \%$ breathing room air and $95 \%$ on $3 \mathrm{~L} \mathrm{O}_{2}$ via nasal prongs. He was returned to the ward and oxygen therapy was continued overnight. The patient felt well enough, four hours after the event, to resume his usual cigarette smoking pattern. A Chest $\mathrm{X}$-ray $24 \mathrm{hr}$ after the incident was normal.

\section{Discussion}

The development of radiographically visible unilateral pulmonary edema indicates an asymmetry, between the hemithoraces, in the forces favouring the development of pulmonary edema. In this case, two mechanisms are suspected. In the lateral position the dependent lung has a disproportionate share of the pulmonary blood flow and elevated hydrostatic pressures. In the lateral position under anesthesia, the diaphragm of the lower lung is elevated more than that of the non-dependent lung. ${ }^{4}$ Nunn $^{5}$ noted that 


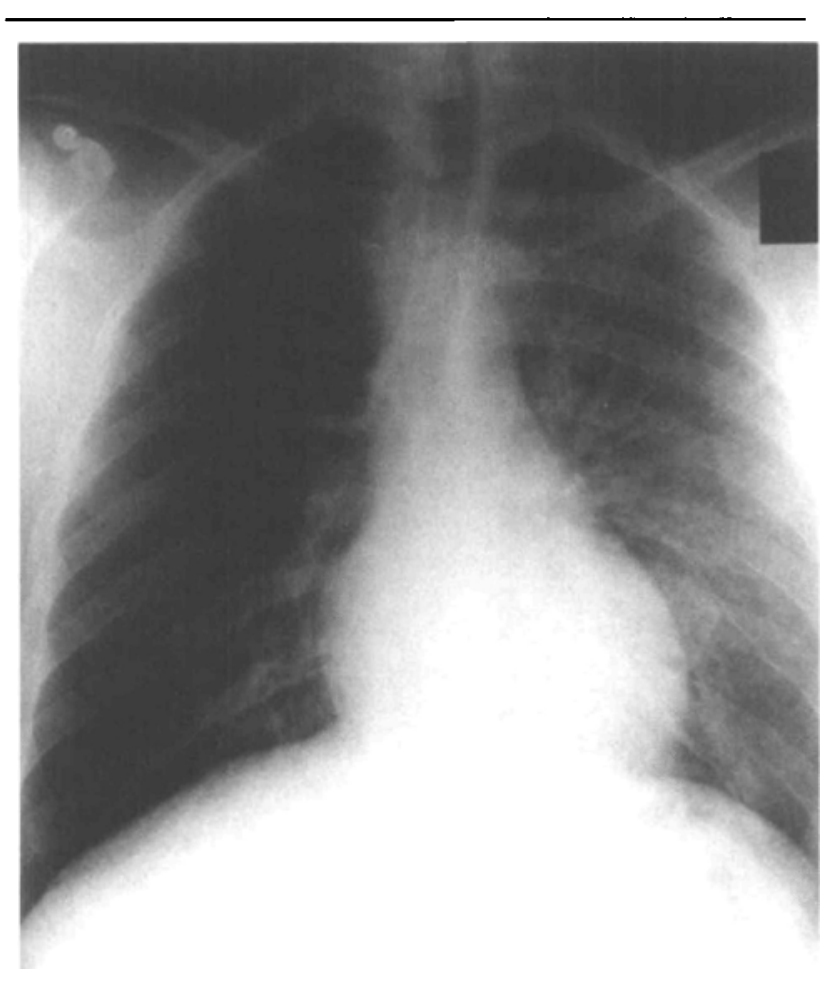

FIGURE Portable AP chest $\mathrm{X}$-ray $30 \mathrm{~min}$ after arrival to PACU.

the capacity and compliance of the interstitium for water are increased at larger lung volumes. Further, with an elevated hemidiaphragm, in the circumstance of maximal effort, there is the potential to generate a more negative pressure relative to the opposite hemithorax because of a greater excursion.

A previous report of unilateral NPPE ${ }^{2}$ illustrates the requirement for a functioning hemidiaphragm to develop pulmonary edema within a hemithorax. The patient developed unilateral NPPE after laryngospasm only on the right side contralateral to a functioning left interscalene block with probable left diaphragm paralysis. In that report, the trachea was extubated and the patient was treated throughout the episode of airway obstruction in the supine position (A. Betts, personal communication). The report by Bourke ${ }^{3}$ also documents right-sided pulmonary edema, which developed during an episode of laryngospasm in the $\mathbf{R}$ lateral position.

The current report describes left-sided unilateral NPPE, confirming that unilateral NPPE can occur in either hemithorax. Although the elevated resting position of the dependent hemidiaphragm may be important in the development of increased negative pressure and the reduced volume of the lung may influence the expression of pulmonary edema, it seems likely that, in the lateral position, hydrostatic forces are of particular importance. Regarding the propensity to accumulate extravascular lung water, Nunn ${ }^{5}$ indicated that, overall, there was a small balance favouring transudation, which is adequately compensated for by the lymphatics. There is, however, considerable regional variation, such that there is a wide safety margin where the microvascular hydrostatic pressure is lowest whereas, in the dependent part of the lung where the hydrostatic pressure is highest, the safety margin is relatively slender. ${ }^{5}$ Thus, the dependent lung is particularly susceptible to relative pulmonary hypervolemia and increased pulmonary venous pressures as outlined by Lang. ${ }^{1}$ The finding that the patient had a lower oxygen saturation in the lateral than in the supine position provides supportive evidence of a relative increase in blood flow to the left lung and a functional asymmetry between the two lungs, consistent with the radiological evidence.

Unilateral NPPE cannot be distinguished from aspiration - especially with an unprotected airway in the lateral position. However, aspiration large enough to produce the parenchymal injury sufficient to produce the X-ray picture of multilobar pulmonary edema, is unlikely to resolve clinically over a few hours. The diagnosis reflects the balance of probabilities, ${ }^{6}$ and in this circumstance, favours NPPE.

Lang ${ }^{1}$ noted that pulmonary edema associated with upper airway obstruction may be under recognized and supported this by quoting an $11-12 \%$ incidence of pulmonary edema in populations requiring active intervention (intubation or tracheostomy) for airway obstruction. The incidence of aspiration in the fasted elective surgical patient, without a history of reflux, is 1 in $2,000-3,000 . .^{7}$ Thus, the patient who has suffered a clinically important episode of upper airway obstruction is at least ten times more likely to have experienced NPPE than aspiration. This reasoning may not be applicable to the case reported by Dr. Bourke, ${ }^{3}$ which involved an appendectomy and required a longer period for resolution. However, NPPE remains an important consideration in the differential diagnosis of unilateral pulmonary findings even in this context.

It is possible that the airway obstruction, which occurred in this case, was at the level of the clenched teeth occluding the LMA. If this occurs, the inflated LMA is capable of maintaining a seal, which will allow the development of pathological subatmospheric intrathoracic pressures. This would support the recommendation to use a bite block during anesthesia with an LMA. 


\section{Conclusion}

Negative pressure pulmonary edema results from the complex interaction of pathological negative intrathoracic pressure and a hyperdynamic state, acting on normal lung physiology. Negative pressure pulmonary edema may occur more frequently than is generally appreciated. A recent case report ${ }^{2}$ has illustrated the development of unilateral NPPE in the hemithorax opposite a paralysed hemidiaphragm. The present report describes the development of unilateral NPPE of the dependent lung during an episode of airway obstruction with the patient in the lateral position. Hydrostatic forces and the elevated position of the diaphragm of the dependent hemithorax in the lateral position are probably the mechanisms involved in the genesis of unilateral NPPE.

\section{References}

1 Lang SA, Duncan PG, Shephard DAE, Ha HC.

Pulmonary oedema associated with airway obstruction. Can J Anaesth 1990; 37: 210-8.

2 Betts $A$, Eggan JR. Unilateral pulmonary edema with interscalene block. Anesthesiology 1998; 88: 1113-4.

3 Bourke $A M$. Unilateral pulmonary oedema following postextubation laryngospasm (Letter). Anaesthesia 1997; $52: 914$.

4 Benumof JL. Respiratory physiology and respiratory function during anesthesia. In: Miller RD (Ed.).

Anesthesia 4th ed. New York: Churchill Livingstone, 1994: 577-620.

5 Nunn JF. Pulmonary oedema. In: Nunn JF. Applied Respiratory Physiology, 3rd ed. London: Butterworths, 1987: 430-9.

6 Kassirer JP. Diagnosis in the public domain. N Engl J Med 1993; 329: 50-1.

7 Gibbs CP, Modell JH. Pulmonary aspiration of gastric contents: pathophysiology, prevention, and management. In: Miller RD (Ed.). Anesthesia 4th ed. New York: Churchill Livingstone, 1994: 1437-69. 